CIUDAD Y TERRITORIO

ESTUDIOS TERRITORIALES

ISSN(P): 1133-4762; ISSN(E): 2659-3254

Vol. LII, № 204, verano 2020

Págs. 277-294

https://doi.org/10.37230/CyTET.2020.204.06

CC BY-NC 4.0

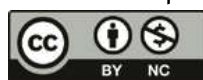

\title{
La iniciativa ciudadana, como origen del cambio urbano. La remodelación del Poblado Dirigido de Orcasitas en Madrid
}

Noelia Cervero-SÁnchez

Universidad Politécnica de Arquitectura. Escuela de Ingeniería y Arquitectura, Universidad de Zaragoza

RESUMEN: La investigación del modelo de intervención aplicado en la remodelación del Poblado Dirigido de Orcasitas (1976-1986) que supone la sustitución de la edificación residencial, la reurbanización y la construcción de equipamientos, muestra una operación en la que el barrio actúa como precursor y campo de experimentación. Se realiza una revisión crítica de los aspectos que condicionan el proceso: el marco legislativo y jurídico; el sistema de gestión; el sistema de financiación y la planificación urbanística y edificatoria. El análisis de estos cuatro ámbitos permite profundizar en un modelo de intervención, cuyo motor es la participación de la población, que abre camino a una operación de escala territorial, la Operación de Barrios en Remodelación de Madrid. La evaluación de este modelo de actuación, favorecido por una serie de circunstancias derivadas del momento histórico y el entorno físico, atiende a la finalidad de optimizar los procesos actuales y ponerlo en valor como impulsor del cambio urbano.

PALABRAS CLAVE: Iniciativa ciudadana; Participación; Cambio urbano; Remodelación; Barrio de Promoción Oficial.

Civic initiative, the origin of urban change. The redevelopment of the Poblado Dirigido de Orcasitas in Madrid

ABSTRACT: The research of the intervention model applied in the redevelopment of the Poblado Dirigido de Orcasitas (1976-1986), that supposed the replacement of the residential blocks and the provision of new infrastructure, reflects an operation in which the neighborhood acts as a precursor and a field of

Recibido: 09.01.2019; Revisado: 14.05.2019

Correo electrónico: ncervero@unizar.es No ORCID: https://orcid.org/0000-0002-1916-5812

La autora agradece los comentarios y sugerencias realizados por los evaluadores anónimos, que han contribuido a mejorar y enriquecer el manuscrito original. 
experimentation. A critical review of the aspects that determine the process is conducted: legislative and legal framework; management; financing system and urban planning. The analysis of these four areas allows to delve into an intervention model whose real driving force is the participation of the residents, which paves the way for an operation of territorial scale, the Operación de Barrios en Remodelación de Madrid. The assessment of this intervention model, favored by a series of circumstances derived from the historical moment and the physical environment, attends to the purpose of optimizing the current processes and point out its value as a driver of urban change.

KEYWORDS: Civic Initiative; Participation; Urban renovation; Redevelopment; Affordable housing neighborhood.

\section{Introducción}

I derecho a la ciudad, con el que el sociólogo francés Henri LefEVBRE (1978) se refiere en el año 1968 al derecho a acceder a todo aquello que aporte calidad de vida urbana según los deseos y necesidades de la población, constituye la consigna principal que a comienzos de la década de los años setenta toma un importante movimiento vecinal en la periferia suburbial consolidada de Madrid. Se fragua en núcleos de infravivienda que, entre los años 1940 y 1963, se construyen en suelo rústico del Plan General de 1946, para proporcionar alojamiento a la inmigración procedente de áreas rurales. Pueden distinguirse dos tipos de asentamiento, que conviven con gran proximidad en zonas marginales situadas principalmente al sur y sureste de la capital: barrios de autoconstrucción, que surgen en parcelaciones ilegales de forma espontánea y con gran precariedad, y barrios de promoción oficial, que se promueven con deficiente calidad y control, y derivan en una rápida y progresiva degradación (BRANDIS, 1983, p. 132). El abandono por parte de la Administración de estos núcleos de chabolismo autoconstruido y oficial, les mantiene al margen de la ciudad sin infraestructuras ni servicios mínimos, cuestión que se suma al hecho de que, al ganar centralidad, son sometidos a una permanente amenaza de expulsión ante planteamientos de carácter especulativo (CASTRO, 1996). En este clima, comienza a generarse una

\footnotetext{
${ }^{1}$ La convivencia de estas áreas en los límites de la ciudad responde al concepto ideológico de "ciudad dual" que CASTELLS (1991, pp. 89-103) introduce en los años ochenta y al que GÓMEZ-MORÁN (1872, pp. 75-76) hace referencia a comienzos de los setenta en referencia al mercado dual como causa de segregación y posible principio de un problema social latente o de un conflicto de clases.

${ }^{2}$ López de Lucio apunta a una "doble transición": de orden político, que aporta voluntad institucional y medios económicos a la operación, y de orden disciplinar, que aporta una nueva forma de proceder en Madrid, apoyada en un intenso movimiento asociativo vecinal y con un fuerte carácter simbólico (LÓPEZ DE LUCIO, 2013, p. 174)
}

conciencia colectiva, cuyo motor central es el derecho a la vivienda digna y la ciudad, por la que los vecinos reclaman adecuadas condiciones de habitabilidad y permanencia en estas áreas de expansión, vacías de contenidos urbanos, a las que han aportado un valor real y simbólico'.

La inestabilidad política del momento histórico, en el que España se prepara para la transición hacia la democracia ${ }^{2}$, facilita el desarrollo de un movimiento asociativo, que reivindica una "deuda social" del Estado, tanto en los barrios de autoconstrucción, ante su contribución al desarrollo urbano y económico de la ciudad, generando mano de obra y plusvalías por la progresiva recalificación de los terrenos, como en los barrios de promoción oficial, ante las condiciones ruinosas de la edificación y la falta de servicios. La fuerza y el alto grado de organización de este movimiento, a la vez democrático y asambleario, que se sirve de cauces institucionales a través de las Asociaciones de Vecinos $^{3}$ (CASTELLS, 1981, pp. 231-238), lleva a la Administración a aceptar su liderazgo, en un programa conocido como Operación de Barrios en Remodelación de Madrid. Se trata de una intervención a gran escala que da respuesta a las necesidades básicas de la población, mediante el derribo y nueva construcción de viviendas y equipamientos en treinta barrios -unas 800 ha y 38.590 viviendas- (FIG. 1), en los que se llevan a cabo profundas transformaciones del tejido urbano ${ }^{4}$ (VINUESA, 1986, p. 71). La complejidad de este importante campo de experimentación residencial

\footnotetext{
${ }^{3}$ La fuerza de estas asociaciones es especialmente destacable en Madrid, donde su grado de auto organización les permite, establecido el Estado democrático, adquirir identidad propia en cada barrio. En 1968 se crea la primera Asociación de Vecinos en Palomeras Bajas, y en 1977 hay sesenta asociaciones legalizadas.

${ }^{4}$ Esta Operación se completa con el Programa de Ocho Barrios (afecta a ocho Poblados de Absorción, a los que se suman tres barrios de promoción oficial) en un intento de reorientación de la intervención pública hacia la rehabilitación, que falla en favor de la remodelación. El total de viviendas de promoción oficial afectadas por ambas operaciones asciende a 23.511 un $23 \%$ del total (DízZ DE PABLO, 2015, pp. 73-74).
} 


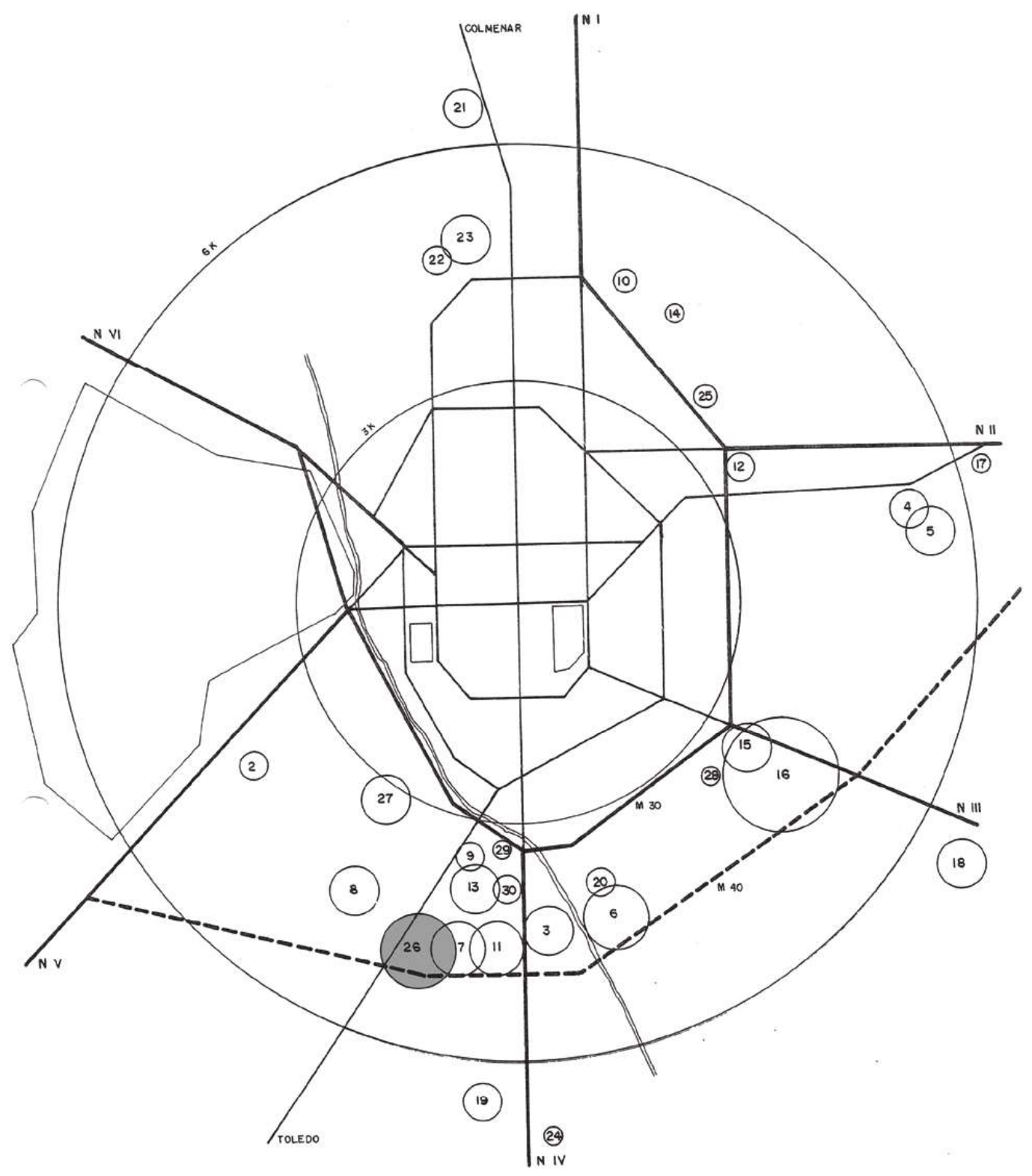

1. Chinchón | 2. Los Cármenes Caño Roto | 3. San Fermín | 4. San Blas I| 5. P. D. San Blas H. | 6. Pozo del Tío Raimundo | 7. Meseta de Orcasitas | 8. Pan Bendito | 9. Zofio | 10. Pinar de Chamartín | 11. Orcasur | 12. San Pascual | 13. Cornisa de Orcasitas | 14. El Carmen | 15. Fontarrón | 16. Palomeras | 17. Canillejas | 18. Uva Vallecas | 19. Uva Villaverde | 20. P.M. Vallecas | 21. Santa Ana Fuencarral | 22. Valdeacederas | 23. Ventilla | 24. Santa Petronila | 25. Marquesa de Amboague | 26. P.D. Orcasitas | 27. Carabanchel| 28. Cruz Blanca| 29. Las Carolinas | 30. Almendrales

FIG. 1/ Situación y proporción de la remodelación del Poblado Dirigido de Orcasitas en relación a las intervenciones de la Operación de Barrios en Remodelación de Madrid.

Fuente: MoYA, S/F, p. $1 .$. 
(LÓPEZ DE LUCIO, 2013, p. 174) con actuaciones en el medio físico, reside en la necesidad de adaptar unos planteamientos generales únicos a las características específicas de cada barrio. El proceso da comienzo en Orcasitas con la intervención en el Poblado Dirigido, cuyo frente vecinal unido a los asentamientos contiguos, actúa como instigador en la lucha por un programa general de remodelación (VINUESA, 1986, p. 76).

Este artículo analiza la intervención que se administra entre los años 1976 y 1986 al Poblado Dirigido de Orcasitas, uno de los barrios oficiales más combativos, incluido en la Coordinadora de Barrios en Remodelación y considerado como interlocutor válido por la Administración (LASSO, 1981, pp. 33-35), que ocupa una posición destacada en la Operación. Ante la gravedad de su situación, la inercia del proceso reivindicativo global alienta a la población del conjunto a interactuar con los diferentes organismos y entidades implicados, para la generación ex novo de un marco legislativo y jurídico, un sistema de gestión y amortización de las viviendas, y una planificación urbanística y edificatoria, que marcan un antecedente para la renovación urbana de la ciudad construida ${ }^{5}$. Esta mirada al pasado, mediante la evaluación de un modelo de actuación protagonizado por los "actores" de la vida urbana, los propios habitantes, en un ejercicio de fuerza sobre los poderes públicos, atiende a la finalidad de conocer sus particularidades, para que puedan ser tenidas en cuenta en la optimización de los procesos actuales.

La metodología que se aplica para el desarrollo del estudio consiste la revisión crítica de aquellos aspectos que condicionan el proceso de intervención en el Poblado Dirigido, teniendo en cuenta la iniciativa y actividad de la población residente y poniéndolos en relación con la Operación de Barrios:

- Marco legislativo y jurídico. Se atiende a las disposiciones y acuerdos que dan respaldo al proceso.

- Sistema de gestión. Se tiene en cuenta el grado de responsabilidad y de implicación de las entidades involucradas.

- Sistema de financiación. Se detallan las fuentes de financiación y la repercusión por vivienda.

\footnotetext{
${ }^{5}$ A pesar de su carácter precursor, no se puede decir que los criterios adoptados en esta intervención rijan la Operación de Barrios en Remodelación que, como afirma LóPEZ DE Lucıo (1981, p. 76), lejos de plantearse como una acción
}

- Planificación urbanística y edificatoria. Se describen los instrumentos de planeamiento urbanístico, la evolución del proceso y los puntos clave del proyecto.

\section{El Poblado Dirigido de Orcasitas en el movimiento vecinal}

La Operación de Barrios en Remodelación constituye una experiencia de urbanismo participativo a gran escala, que alcanza un alto grado de madurez y organización desde la conciencia colectiva para hacer frente a objetivos comunes vinculados al arraigo a un espacio que, aun siendo hostil, se considera propio (RodRíGUEZ VILLASANTE, 1989, p. 54). La reivindicación ciudadana, formulada como lucha vecinal, se inscribe en el contexto de los llamados movimientos sociales urbanos de los años sesenta. Las primeras asociaciones se crean en torno a organizaciones religiosas o familiares, que se integran en grupos ligados al mundo obrero y a la izquierda política. Paulatinamente ganan legitimidad frente a la opinión pública gracias a la prensa, que denuncia su situación y se hace eco de las protestas y negociaciones con los organismos públicos. A mediados de los años setenta, se dan varias circunstancias que recrudecen la lucha, como son: la crisis económica, el apoyo estatal a viviendas destinadas a las clases medias y altas, y la aprobación de planes parciales de tipo especulativo que buscan la expropiación de áreas consolidadas. Durante este periodo, las Asociaciones de Vecinos adquieren un gran protagonismo, con la confluencia de reivindicaciones que provienen de barrios de infravivienda, entre los que cabe señalar por su visibilidad el Pozo del Tío Raimundo, Palomeras Bajas y la Meseta de Orcasitas, y de barrios de promoción oficial, con papel destacado por la urgencia de su protesta, del Poblado Dirigido de Orcasitas (MoYA, 1987, pp. 7-8).

En el Poblado Dirigido de Orcasitas la Asociación de Vecinos tarda en formarse, debido a la escasa cohesión de su población y la desvinculación del entorno, propias de este tipo de promociones. Los Poblados Dirigidos, como actuaciones oficiales con vocación de permanencia, acogen un vecindario formado por trabajadores industriales, funcionarios y miembros de los cuerpos de seguridad del Estado afines al régimen, que disfrutan

coherentemente asumida por la Administración pública consiste en una serie de respuestas particulares a demandas concretas, en actuaciones escasamente relacionadas entre sí. 

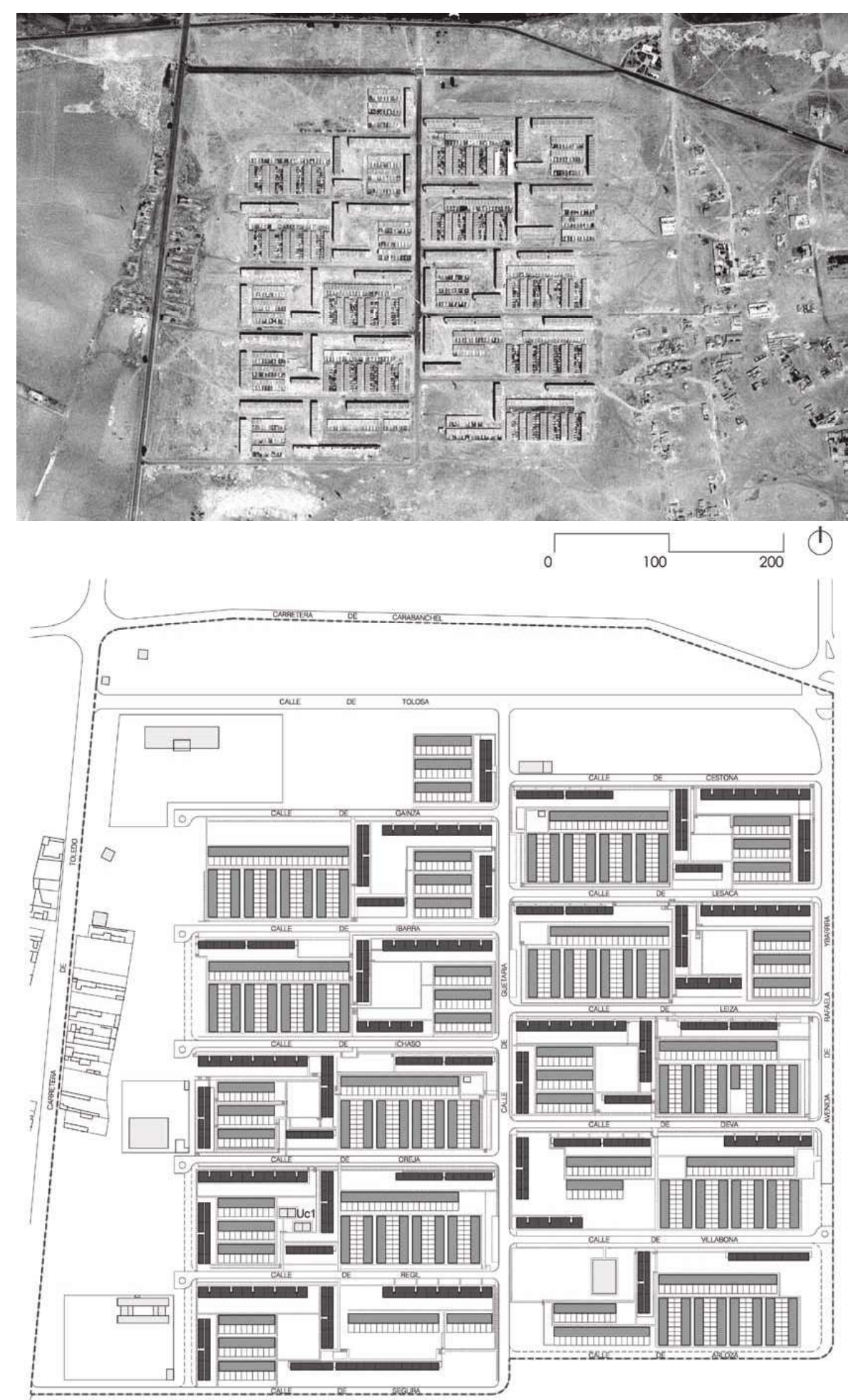

FIG. 2/ Poblado Dirigido de Orcasitas, 1961-1967.

Fuente:Sistema de Información Territorial del Instituto de Estadística de la Comunidad de Madrid y elaboración propia. 
de un acceso diferido a la propiedad de su vivienda (LASso, 1981, p. 17). Esta población diversa, pero en su mayor parte normalizada, se considera una minoría selecta en la periferia y marca sus diferencias respecto al resto de promociones oficiales y a los núcleos chabolistas vecinos (Denche \& Rodríguez Villasante, 1987, 28).

El Poblado Dirigido de Orcasitas es promovido entre los años 1957 y 1963 por la Gerencia de Poblados Dirigidos, bajo la tutela del Instituto $\mathrm{Na}$ cional de la Vivienda (INV) dentro de las medidas arbitradas por el Plan de Urgencia Social (MoYA, 1983 , p. 38). El proyecto de 2.964 viviendas realizado por los arquitectos Rafael Leoz de la Fuente y Joaquín Ruiz Hervás ${ }^{6}$, se construye en unos terrenos de 40,27 ha, alejados del continuo urbano de Madrid, en la confluencia entre la carretera de Toledo y la avenida de los Poblados ${ }^{7}$. El ámbito prácticamente cuadrado, tiene ordenación reticular, con una vía longitudinal dirección norte sur y seis transversales, que delimitan grandes manzanas, en las que la edificación se dispone de forma libre en bandas paralelas y perpendiculares a las vías en un ejercicio de composición neoplasticista (FIG. 2). Se trata de edificación en altura, con 1707 viviendas en bloques lineales de $\mathrm{PB}+5$, y en superficie, con 1.257 viviendas unifamiliares en hilera de $\mathrm{PB}+1$ y patio en uno de los frentes, que ofrecen una gran variedad de tipos de vivienda. Se acogen a la Ley de Renta Limitada de 1954, perteneciendo las colectivas y parte de las unifamiliares a la $3^{\text {a }}$ Categoría, y el resto, adjudicadas a los estratos más bajos mediante un sistema de prestación personal durante la obra, al tipo Social. En cuanto a los servicios comunitarios, aunque no pueden acometerse en el proyecto de 1956, son tenidos en cuenta en un Plan de Actuación sobre el barrio, elaborado en 1962 por el Servicio de Programación y Coordinación del INV y en un Plan Parcial, redactado en 1970 por Ruiz Hervás y aprobado dos años después ${ }^{8}$. Según estos documentos, las manzanas residenciales deberían estar bordeadas por bandas verdes de protección en las que se ubicarían los equipamientos necesarios para elevar el conjunto a la categoría de núcleo urbano. Sin embargo, no llegan a materializarse ni la urbanización del conjunto ni sus dotaciones ${ }^{9}$, en cuyo lugar se mantienen las chabolas preexistentes, borrando la condición ideal que ofrecía el proyecto (FERNÁNDEZ Galiano, 1989, p. 82-87) (FIG. 3).

La remodelación del poblado viene motivada por un problema de asientos diferenciales en las cimentaciones, que no están calculadas para el terreno de arcillas expansivas sobre el que se sitúa (SERRANO, 1999, pp. 172-173). Las primeras grietas aparecen a los pocos meses de terminar la ejecución de la estructura de las viviendas, y en 1961 son, en palabras de LeOz y Ruiz HERVÁs (1961b, p. 924), un asunto "enormemente escandaloso". A pesar de los reformados del proyecto y de las medidas que se toman en este primer momento, los asientos, lejos de estabilizarse como se esperaba, se van agravando hasta mermar la habitabilidad e incluso la seguridad de las edificaciones, y conducen a una situación crítica en 1975, cuando junto a los primeros realojos se extiende la alarma social.

La limitada consolidación del tejido social del poblado (MANZANO, 1979, p. 637-640), lleva a los residentes a tratar los primeros problemas de forma individual y, sólo ante la inutilidad de esta vía, comienzan a buscar soluciones colectivas. Tampoco contribuye a su coordinación la falta de conexión con barrios cercanos, con los que mantiene una clara diferenciación debido a su sentimiento de identificación con el orden dominante, opuesto a la condición marginal de éstos (DENCHE \& RODRÍGUEZ VILLASANTE, 1987, pp. 28-32). Los habitantes del Poblado Dirigido se consideran parte de la ciudad, y se incorporan al proceso forzados por el miedo a perder su supuesta integración, a causa de la ruina de sus viviendas. A pesar de ello, la Asociación de Vecinos, que se consolida entre 1974 y 1975 y se mantiene activa hasta 1984, une su actividad a las veteranas Asociaciones de la Meseta y Orcasur, que representan a los asentamientos autoconstruidos y los poblados marginales próximos. Este apoyo entre asociaciones, les lleva a ocupar una posición destacada en la Operación de Barrios en Remodelación de Madrid, consiguiendo no solamente estar representadas en la Comisión de Seguimiento mixta que lo redacta y regula, sino llevar a cabo un verdadero proceso de participación

\footnotetext{
${ }^{6}$ Proyectos de la primera y segunda fases de construcción del Poblado de 1957 y 1958, y Proyectos reformados y adicionales de cimentaciones complementarias de 1960, consultados en el Archivo Regional de la Comunidad de Madrid. ${ }^{7}$ Su localización en zona no edificable o rústica es legalizada en el Plan de 1963, que incorpora todos los barrios existentes a su zonificación, con lo que se contribuye a legalizar los asentamientos irregulares del cinturón de Madrid (MoYA, 1983, p. 79). ${ }^{8}$ Plan de Actuación sobre el barrio de 1962 y Plan Parcial de

y la Delegación de Patrimonio del Instituto de la Vivienda de Madrid (IVIMA)

${ }^{9}$ La precariedad de la urbanización se debe a una limitación del presupuesto protegible de la Ley de Renta Limitada y una ausencia de mejoras posteriores por parte de la Gerencia del Poblado Dirigido, a quien corresponde la propiedad del suelo desde 1967.

Los servicios son provisionales, como aulas y consultorios habilitados en viviendas, una iglesia prefabricada y un merca-
} Ordenación del Poblado de 1970, consultados en el Archivo do eventual. 

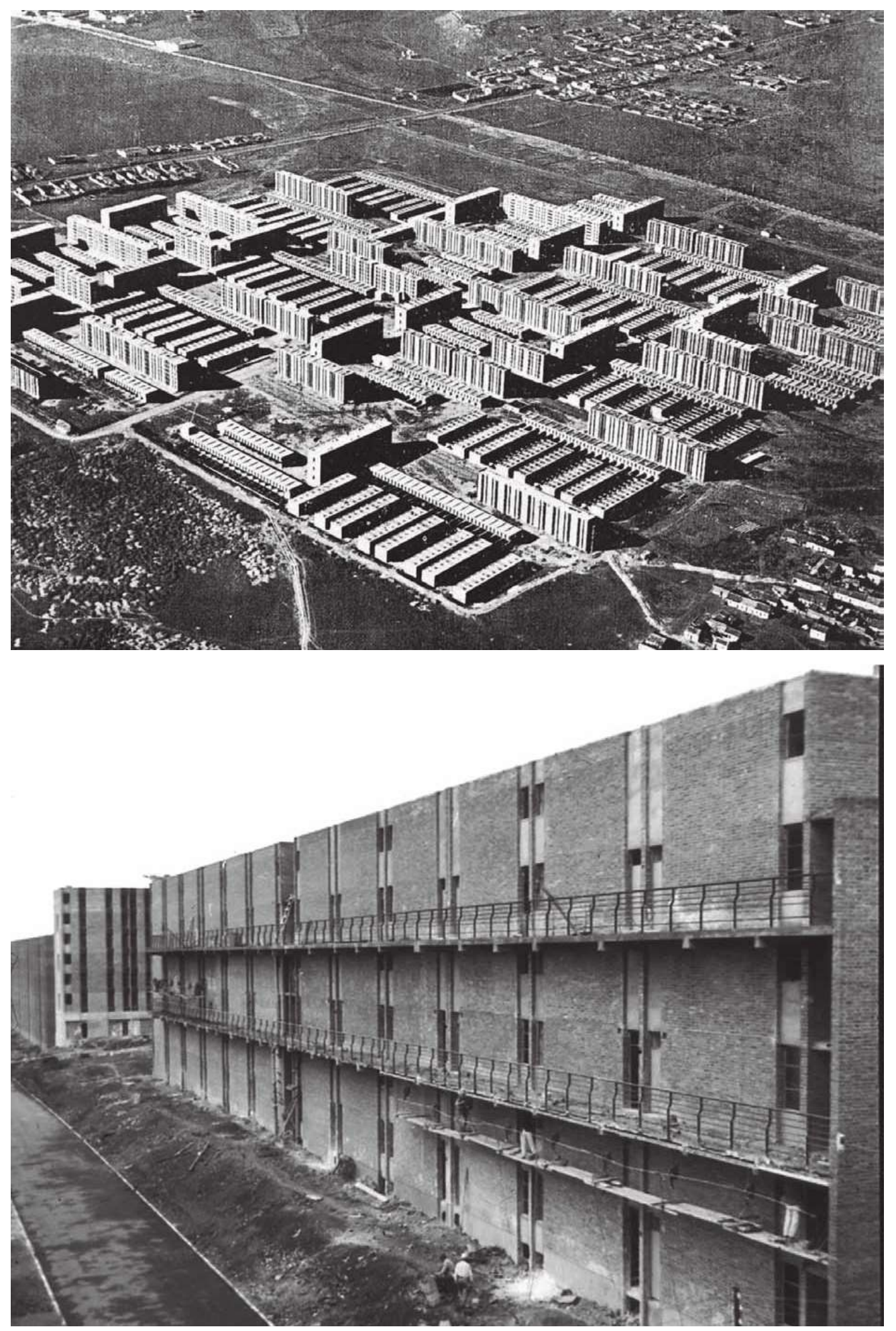

FIG. 3/ Poblado Dirigido de Orcasitas, 1961 y 1960.

Fuente: Leoz, 1961a, p. 857 y colección C. Portillo. Archivo Regional de la Comunidad de Madrid.. 
vecinal ${ }^{10}$. En la representación conjunta, su importante papel al frente de la Coordinadora de Barrios en Remodelación, formada en diciembre de 1978 e integrada por todos los barrios pendientes de remodelación a excepción de Vallecas y Palomeras, consigue el respaldo oficial de la Administración, tras décadas de ausencia en la periferia (VINUESA, 1986, p. 73-74). En su funcionamiento interno, el alto grado de participación de los vecinos con una presencia masiva en las asambleas y convocatorias, aporta un importante respaldo a las decisiones y facilita su integración en las tareas de organización y seguimiento (HERNÁNDEZ AJA \& VELÁZQUEZ, 1987, p. 40).

\section{Marco legislativo y jurídico}

La intervención en el poblado es responsabilidad del INV, al que en 1961 le son transferidas las funciones de la Gerencia de Poblados Dirigidos, hasta entonces organismo encargado de su dirección y representación jurídica. Para que pueda llevarse a cabo, son necesarios una serie de cambios en la legislación, que hasta ese momento no contemplaba desarrollos de estas características y, ante la conflictividad de la situación, el Estado se ve obligado a desarrollar. La reivindicación, centrada en evitar desplazamientos de población fuera de la zona y reclamar responsabilidades a la Administración encargada de su mantenimiento, da como resultado un primer documento oficial donde se reconoce la necesidad de la renovación urbana, el Decreto 212/1976, de 23 de enero, de actuaciones urgentes del Instituto Nacional de la Vivienda en el Poblado Dirigido de Orcasitas. Con él, el Ministerio de Obras Públicas y Urbanismo (MOPU) autoriza al INV a financiar las obras precisas para que el poblado "pueda volver a desempeñar la función social para la que fue construido", adelantándose al comienzo de la Operación general.

Tras una primera fase que se destina al realojo de la población del conjunto, y con el proyecto de la siguiente fase finalizado, la aprobación del Real Decreto-ley 31/1978, de 31 de octubre, sobre política de Viviendas de Protección Oficial, con desarrollo en el Real Decreto 3148/1978, supone

\footnotetext{
${ }^{10}$ La presión ejercida con la gran presencia en la prensa durante los primeros años de la remodelación, se refleja en titulares como: "Movilización vecinal en el Poblado Dirigido de Orcasitas" El País, 3-12-1977; "Con Orcasitas de fondo, cargas y palos ante Obras Públicas" Diario 16, 5-12-1977; "Orcasitas, los vecinos proponen su remodelación" Diario 16, 27-2-1977; "Orcasitas el barrio más polémico de Madrid" YA, 16-3-1978; "Los vecinos de Orcasitas, hartos de esperar las licencias" El Periódico, 10-1-1979, etc.

11 Con declaraciones a la prensa como las recogidas en la publicación "Del barro al barrio. La Meseta de Orcasitas"
}

un freno para el proceso, por las restricciones que introduce respecto a la legislación anterior. Se ve afectada con ello la viabilidad de las nuevas viviendas, tanto del Poblado Dirigido como del resto de barrios que querían sumarse a la remodelación, lo que desencadena un periodo de fuerte forcejeo entre las Asociaciones de Vecinos y el Estado, que trata de eludir su responsabilidad.

En una coyuntura política de gran tensión, en plena transición y con la incertidumbre de la nueva realidad política, el Gobierno central muestra su apoyo a la Operación con una visita en $1977^{11} \mathrm{del}$ Ministro Joaquín Garrigues Walker al Poblado Dirigido y la Meseta de Orcasitas, acción que muestra la notoriedad de su reivindicación (MANGADA, 1987, p. 51). A este respaldo oficial se une el de la industria de la construcción, que busca salir de la crisis en la que se encuentra desde hace años, y el apoyo municipal, que ante la proximidad de las primeras elecciones democráticas, favorece la aprobación de la Orden Comunicada de 24 de Mayo de 1979 del MOPU, con el desbloqueo de la Operación de Barrios en Remodelación. El mínimo rango legal de esta Orden, se relaciona con la escasa voluntad de llevarla adelante y su particularización a unos núcleos muy concretos de Madrid, evitando su generalización en la capital o en todo el país, que al Estado le hubiera resultado inasumible (MoYA, 1987, p. 8-9). Su contenido coincide con las propuestas que la Coordinadora de Barrios envía al Ministerio el 23 de febrero de 1979 (VINUESA, 1987, p. 4-5), lo que da buena muestra de la influencia que ejerce el movimiento vecinal, con la experiencia de los primeros procesos como el del Poblado Dirigido de Orcasitas $^{12}$.

Dentro de este marco normativo específico que reconoce el compromiso del Estado, se recogen particularidades solo aplicables a este Programa, como son: el realojo de la población en los propios barrios; el respeto al régimen de propiedad; la indemnización de la vivienda antigua; la promoción directa de las viviendas nuevas; programas unitarios de actuación y condiciones especiales de renta y financiación (VINUESA, 1986, p. 77). Estas particularidades asumen decisiones tomadas como fruto de la negociación con los vecinos,

(MARTin ARnORIAgA, 1986, p. 182), entre las que puede destacarse "Se ven aspectos que uno creía que no eran lícitos en una sociedad humana" YA, 18-12-1977. Ante la insistencia de los vecinos, los encuentros con el Ministro continúan el año siguiente: "El poblado no pacta: ¡Garrigues firma el acta!" Diario 16, 19-6-1978; "El Ministro Garrigues con un grupo de vecinos del poblado de Orcasitas" YA, 10.8.1978.

12 Junto a él, los barrios autoconstruidos del Pozo del Tío Raimundo, la Meseta de Orcasitas y Palomeras. La Orden Comunicada afecta en el Poblado Dirigido de Orcasitas a las 1.563 viviendas pendientes de iniciarse a partir del año 1980. 
que se consideran derechos previos adquiridos. Conllevan además la modificación del marco jurídico de referencia, el Real Decreto Ley 31/1978, de 31 de octubre, citado anteriormente, para asumir la normativa previa mediante el Real Decreto 2960/1976, de 12 de noviembre, que aplica módulos de vivienda Social y no de Protección Oficial, haciendo las viviendas más accesibles a todo tipo de usuario. Con este documento, la Administración marca el punto de partida del Programa, aportando un soporte legal de rango discutible y cargado de indefiniciones, que se resuelven a medida que avanza el proceso en las negociaciones con el movimiento vecinal (VINUESA, 1987, p. 4).

Esta Orden Comunicada es complementada y ampliada por Acuerdo del Consejo de Ministros el 12 de febrero de 1982, y se formaliza en el Real Decreto 1133/1984, de 22 de febrero, consolidando definitivamente la Operación de Barrios desde un punto de vista legal ${ }^{13}$. En él se recogen todas las disposiciones y acuerdos que se habían producido desde el año 1979, y en ocasiones sirve para validar aspectos no contemplados en las normas vigentes (VINUESA, 1987, p. 9-10), como son: el incremento de presupuestos; la exención de disponibilidad previa de los terrenos; la ampliación de la superficie de las viviendas; la posibilidad de superar los porcentajes de inversión previstos; y las deducciones de los propietarios. Asimismo, ratifica las condiciones de cesión y financiación de las nuevas viviendas establecidas en la Orden Comunicada, legalizando decisiones tomadas en sus fases iniciales, cuando más de la mitad de las viviendas del Programa de Barrios habían sido construidas, y la actuación en el Poblado Dirigido estaba finalizando.

\section{Sistema de Gestión}

El detonante de la intervención en el Poblado Dirigido de Orcasitas tiene lugar en 1975, con el conflicto social provocado por un gran número de desalojos fuera del barrio debido al estado de la edificación. Hasta ese momento, las labores de recalce en las viviendas unifamiliares conllevan movimientos de población a hogares vacíos dentro del poblado, pero los problemas en los primeros bloques hacen necesarios traslados a otros ámbitos de la capital. La negativa a aceptar este sistema de realojos se manifiesta en una

${ }^{13}$ La demora de su publicación hasta el 18 de junio, junto a dos decretos que ponen de manifiesto su interdependencia del Decreto de Transferencias de 13 de junio de 1984, permite intuir la importancia del Programa en el acuerdo de transferencias a la Comunidad. La responsabilidad del Programa de Barrios se importante protesta vecinal, que parte de la demanda de evitar desplazamientos en la zona e impulsa la consolidación de la Asociación de Vecinos y su organización en las negociaciones con la Administración, dando lugar a un tipo de colaboración singular (HERNÁNDEZ AJA \& VELÁZQUEZ, 1987, pp. 37-39).

Los acuerdos alcanzados de manera previa a la intervención, permiten a los vecinos desarrollar estructuras y mecanismos a todos los niveles e incidir de forma directa en la planificación y la toma de decisiones, que se coordinan y ejecutan a través de la Administración (DENCHE \& ALGUACIL, 1991, p. 140). Ésta responde ante la iniciativa de la población residente, asumiendo la gestión y promoción de las obras de construcción y urbanización del nuevo poblado. Sigue las normas para viviendas sociales de promoción directa en las que el INV aporta los fondos necesarios procedentes de los Presupuestos Generales del Estado y contrata las obras con la empresa constructora, eliminando toda clase de acción particular. Se sirve de dos órganos gestores, el Instituto para la Promoción de la Vivienda (IPPV) que se encarga de la promoción, y la Comisión de Planificación Metropolitana de Madrid (COPLACO), que lo hace de la adquisición del suelo. EI IPPV encomienda la operación a la Delegación Provincial de la Vivienda, una unidad administrativa con escasez de medios que, aunque cercana a los vecinos, supone un filtro o amortiguador para el Ministerio (MoYA, 1987, p. 32-33). La falta de infraestructura de este organismo para acometer la Operación, tiene como consecuencia que la promoción y control de los últimos contratos de obra del poblado, sean realizados por la Sociedad Estatal de gestión para la Rehabilitación y Construcción de Viviendas (SGV), antiguo VISOMSA, que como empresa mixta actúa con mayor eficacia y rapidez.

Esta estructura pública ejecuta lo pactado con la población, que toma las riendas del proceso, excediendo el ámbito de la participación y asumiendo funciones propias de la gestión, inicialmente desde la organización vecinal y a medida que se consolida el Programa, vinculada a la organización general. Durante los primeros meses de 1977, se forma una organización que emerge de la Asociación, como se especifica en el comunicado de Asamblea General de 14 de marzo de 1977, redactado por los vecinos. Su estructura abarca todos los niveles, mediante la división del poblado

transfiere a la Comunidad de Madrid, con acuerdo de la Administración central de financiarlo, fiscalizarlo y administrar la política correspondiente a través del Instituto de la Vivienda de Madrid (IVIMA) (ORganización PARA La CoOperación y EL CESARROLLO ECONÓMICO, 1988, pp. 38-40). 
en once zonas operativas, correspondientes a las diez manzanas residenciales más las viviendas de realojo, que son representadas por portavoces y delegados de zona. Éstos actúan como agentes intermedios que generan corrientes de información y opinión con un doble sentido: hacia los vecinos, recogiendo sus propuestas en reuniones y asambleas de zona, y hacia la Asociación, llevándolas a la Asamblea General, donde son discutidas para tomar decisiones. La bidireccionalidad en la comunicación se hace posible por la implantación de una red organizativa basada en la diversidad del tejido social y la actividad en la calle (LEÓN \& AlgUACIL, 1987, p. 36).

La participación de los vecinos en la gestión se formaliza con una segunda Orden Comunicada, de 8 de noviembre de 1979, por la que se aprueba una Comisión Coordinadora que preside el Delegado Provincial del MOPU, e integran, junto a los representantes de los diversos organismos implicados -INV, COPLACO, Gerencia de Urbanismo, etc.-, los delegados de las Asociaciones de Vecinos. En la misma dirección, el 9 de mayo de 1980 se promulga una Orden Ministerial para la agilización de las actuaciones del MOPU en la promoción directa de las viviendas que, ante operaciones de urgencia y especial complejidad, reconoce equipos específicos de trabajo, que denomina Comisiones de Seguimiento (VINUESA, 1987 , p. 5-7). Son establecidas por el INV, dependen del Delegado provincial y cuentan con representación de cada uno de los barrios de la Orden Comunicada. En el Poblado Dirigido de Orcasitas, la Comisión de Seguimiento normaliza la implicación de la población en el desarrollo de tareas organizativas y de gestión desde el comienzo de la operación, y da paso a colaboraciones específicas hasta su finalización, ocupándose de funciones como: la gestión de actuaciones vinculadas a la coordinación de los organismos actuantes, la organización de la población, la elaboración de Censos de residentes, la regulación de realojos provisionales y definitivos, la redacción del programa de actuaciones, la toma de decisiones en el desarrollo del proyecto, la gestión de trámites como licencias de obras o actas de recepción y el seguimiento de las obras para su realización acorde a los criterios acordados.

Alo largo de todo el proceso, los vecinos son acompañados por técnicos y profesionales comprometidos con el movimiento vecinal, que proceden

\footnotetext{
${ }^{14} \mathrm{El}$ concepto de advocacy planning surge de la relación que Paul DAVIDOFF (1965) establece entre la figura del procurador judicial (advocate) y del urbanista (planner). Según el autor, el procurador urbanístico debe facilitar la relación entre la Administración y el interés de grupos específicos para resolver una
}

de la Universidad o de partidos en clandestinidad y grupos liberales en el contexto del último franquismo (VINUESA, 1986, p. 76). Se ponen a disposición de las Asociaciones de Vecinos para asesorarlas en la planificación y gestión urbana y empoderarlas en las relaciones con la Administración, práctica que en el mundo angloamericano se conoce como advocacy planning o procuración urbanística ${ }^{14}$. Estos técnicos, involucrados en el proceso de cada barrio y con una gran influencia en el mismo, tienen un conocimiento directo de los problemas y aportan su apoyo facultativo y especializado a la población (MOYA \& FERNÁNDEZ, 2011, pp. 8-9). El asesoramiento en el Poblado Dirigido es realizado por Eduardo Hernández, arquitecto de la Coordinadora de Barrios, que en una primera etapa, cuando las actuaciones de la Administración resultan insuficientes, ofrece soporte técnico a las reivindicaciones frente a la amenaza de expulsión y formula alternativas a los diferentes problemas, y en una segunda etapa, ejerce como técnico de confianza de los vecinos, formando parte de equipos mixtos con los arquitectos contratados por el Ministerio ${ }^{15}$ (HERNÁNDEZ, 1981, p. 82). Se genera así un modelo de intervención que permite a los residentes un control sobre la Operación, sobre el proyecto de su barrio y su vivienda, y sobre la ejecución de los mismos, que altera la lógica habitual de desarrollo urbano.

\section{Sistema de financiación}

La Operación de Barrios en Remodelación carece de una estrategia integral de actuación y un acuerdo político previo que determine una recuperación concreta de la inversión. En su lugar, la Administración acuerda cada decisión y ejecuta aquellas reivindicaciones que se deciden por consenso, absorbiendo las consecuencias económicas de las sucesivas mejoras y prolongando los plazos comprometidos. Esta falta de programación económica repercute en la distribución temporal y espacial de los recursos. Desde el punto de vista temporal, la ausencia de una previsión de presupuestos de inversión anuales influye negativamente en la eficacia de la operación y genera incertidumbre entre los agentes implicados, afectando a la calidad de los proyectos, la capacidad de las empresas constructoras, y la organización de la Administración (MoYA, 1987, pp. 12-16). En la remodelación del Poblado

situación conflictiva o mejorar la condición urbana participando en el proceso político.

${ }^{15} \mathrm{El}$ arquitecto de la primera fase es elegido por la Administración, pero ante las protestas vecinales, que reclaman técnicos paritarios, para las siguientes fases se cuenta con arquitectos independientes. 
Dirigido de Orcasitas, esta cuestión provoca una reducción de la confianza vecinal en la finalización del proceso, debido a que carece de referentes de actuación previa. Desde el punto de vista espacial, se produce una variación de criterios en los distintos barrios, tanto en la adquisición del suelo como en el desarrollo de las actuaciones, con considerables diferencias de inversión por metro cuadrado construido (MoYA, 1987, p. 29). En este aspecto, el Poblado Dirigido se ve favorecido, al formar parte de los barrios más reivindicativos y con un papel más relevante en las negociaciones con la Administración, obteniendo una repercusión por metro cuadrado construido por encima de la media de $274,38 €\left(45.653,00\right.$ ptas. $\left./ \mathrm{m}^{2}\right)$, con $311,30 €\left(51.796,00\right.$ ptas. $\left./ \mathrm{m}^{2}\right)$, y una inversión total de 102,7 millones $€$ (17.087 millones de pesetas) hasta julio de 1986 (FIG. 4).

Las condiciones de cesión de las viviendas, se plantean para toda la Operación con el único criterio de pertenencia de los adjudicatarios al barrio, en función de los Censos que en el Poblado Dirigido elaboran los vecinos, homogeneizando tanto el tipo de vivienda como las condiciones de pago, con independencia de la diversidad socioeconómica de la población, y tomando las exigencias más favorables (MoyA, 1987, p. 15-16). El precio se fija con el módulo o valor tipo del metro cuadrado construido emitido por el INV en el año 1979 para vivienda social, lo que supone una situación ventajosa respecto al módulo de vivienda de promoción pública que les correspondería, sujeto al Real Decreto $3148 / 1978$, al reducir los precios en un porcentaje en torno al $10-15 \%$. Además, del importe total de cada vivienda son deducidos: la amortización de la antigua vivienda, actualizada por el INE; un porcentaje del $7-30 \%$ a fondo perdido como subvención de la Administración por la Ley de Promoción Directa; y la revalorización del terreno, que no es expropiado sino cedido a las autoridades para su urbanización. La forma de financiación plantea plazos de amortización de 35 a 50 años y consiste en: una entrega inicial de un 5\% del precio de venta, con excepciones para los casos más desfavorecidos; un anticipo sin interés del $75 \%$; y un préstamo máximo del $20 \%$ con un interés anual del $5 \%$ (CASTRO, 1996).

Aunque estas condiciones quedan fijadas al inicio de la Operación, no existe infraestructura suficiente para sistematizar los cobros hasta que se produce la transferencia de funciones a la Comunidad de Madrid, por lo que todas las viviendas son facturadas a partir de octubre de 1985. En consecuencia, las primeras viviendas del Poblado Dirigido, habitadas en 1979, no empiezan a pagar amortizaciones o rentas a la Administración hasta ese momento. La recuperación de la inversión, por tanto, se dilata y además se ajusta al módulo del año de ocupación de la vivienda sin actualización del IPC, según las negociaciones realizadas durante ese tiempo. Esta medida incrementa las ventajas sobre los planteamientos iniciales, favoreciendo principalmente a los primeros barrios en los que se interviene (MoyA, 1987 , p. 61). Por otra parte, como el precio de venta o alquiler de las viviendas es fijo en función del módulo vigente, los barrios en los que se realiza una mayor inversión aportan un menor porcentaje de recuperación. Este es el caso del Poblado Dirigido de Orcasitas, con una recuperación media de la inversión realizada en suelo y obra menor al $27 \%$, inferior a la media de la Operación del 35,76\% hasta julio de 1986 (MoYA, 1987 , p. 15). Las condiciones de amortización de las viviendas y el reducido índice de recuperación del capital invertido, llevan a pensar que los responsables de la Administración no hubieran aceptado estas cifras conscientemente en 1979. Se pone con ello de manifiesto el poder de la lucha vecinal, que beneficia en mayor medida a barrios como el Poblado Dirigido, que afrontan la remodelación en un momento temprano y ocupan una posición destacada en el diálogo con las entidades públicas implicadas.

\begin{tabular}{|c|c|c|c|c|c|c|c|c|c|}
\hline & 1979 & 1980 & 1981 & 1982 & 1983 & 1984 & 1985 & 1986 & Total \\
\hline $\begin{array}{l}\text { Inversión } \\
\text { Millones } €\end{array}$ & 5,5 & 23,2 & 14,6 & 12,3 & 212,5 & 7,5 & 6,2 & 0,9 & 102,7 \\
\hline Millones pts. & $4.244,7$ & $3.862,2$ & $2.424,3$ & $2.052,6$ & $2.081,9$ & $1.255,0$ & $1.014,0$ & 152,3 & $17.087,0$ \\
\hline & \multicolumn{3}{|c|}{ Inversión total } & \multicolumn{3}{|c|}{ Repercusión por vivienda } & \multicolumn{3}{|c|}{ Repercusión por $\mathrm{m}^{2}$ construido } \\
\hline$€$ (cte 1986) & \multicolumn{3}{|c|}{$102.695 .000,00$} & \multicolumn{3}{|c|}{$32.012,00$} & \multicolumn{3}{|c|}{311,30} \\
\hline Pesetas & \multicolumn{3}{|c|}{$17.087 .000 .000,00$} & \multicolumn{3}{|c|}{$5.326 .350,00$} & \multicolumn{3}{|c|}{$51.796,00$} \\
\hline
\end{tabular}

FIG. 4/ Inversión en obra hasta 1986, incluyendo construcción y urbanización, y repercusión por vivienda y por metro cuadrado construido en $€$ cte de 1986. 


\section{Planificación urbanística y edificatoria}

La remodelación del poblado, desarrollada entre los años 1976 y 1986, supone la sustitución de toda la edificación contenida en las manzanas residenciales del conjunto, así como la reurbanización de las mismas y de su viario perimetral. Como el resto de la Operación de Barrios, no se rige por un planeamiento específico ${ }^{16}$, sino por criterios de ordenación parcial que atienden a diversos condicionantes: el área de actuación, con la delimitación original; el número de viviendas, según las restricciones de ocupación del Plan General de 1963; el proceso de obra, en el que se procura realojo continuo a la población dentro del poblado; y la participación vecinal que lidera la toma de decisiones condicionando todas las escalas del proyecto ${ }^{17}$.

La intervención se realiza en cinco fases escalonadas acordes con las Ordenanzas Municipales, que varían en función de las sucesivas modificaciones del Plan General de 1963, y con figuras de planeamiento, que más allá de los fines encomendados por la Ley del Suelo, responden a aspectos pragmáticos para facilitar su aprobación (MoYA, 1987, 38). Estos documentos mantienen para el área la calificación de edificación abierta, con el objeto de concentrar el volumen edificable, facilitar la gestión del realojamiento y reducir la repercusión del suelo en el valor de las viviendas. Con respecto a las normas de construcción, las 3.208 viviendas del nuevo poblado, correspondientes a las del conjunto original más unidades de realojo, se acogen a la Normativa de Vivienda de Protección Oficial, con criterios de diseño y calidad de Viviendas Subvencionadas y Sociales, que se suceden en el tiempo.

La exigencia de la población de ser realojada dentro del poblado, se soluciona inicialmente con un tipo de viviendas prefabricadas, denominadas fillods, que se sitúan en espacios interbloque. Debido a sus escasas condiciones de habitabilidad, las viviendas provisionales que se levantan a continuación, entre los años 1976 y 1977, son
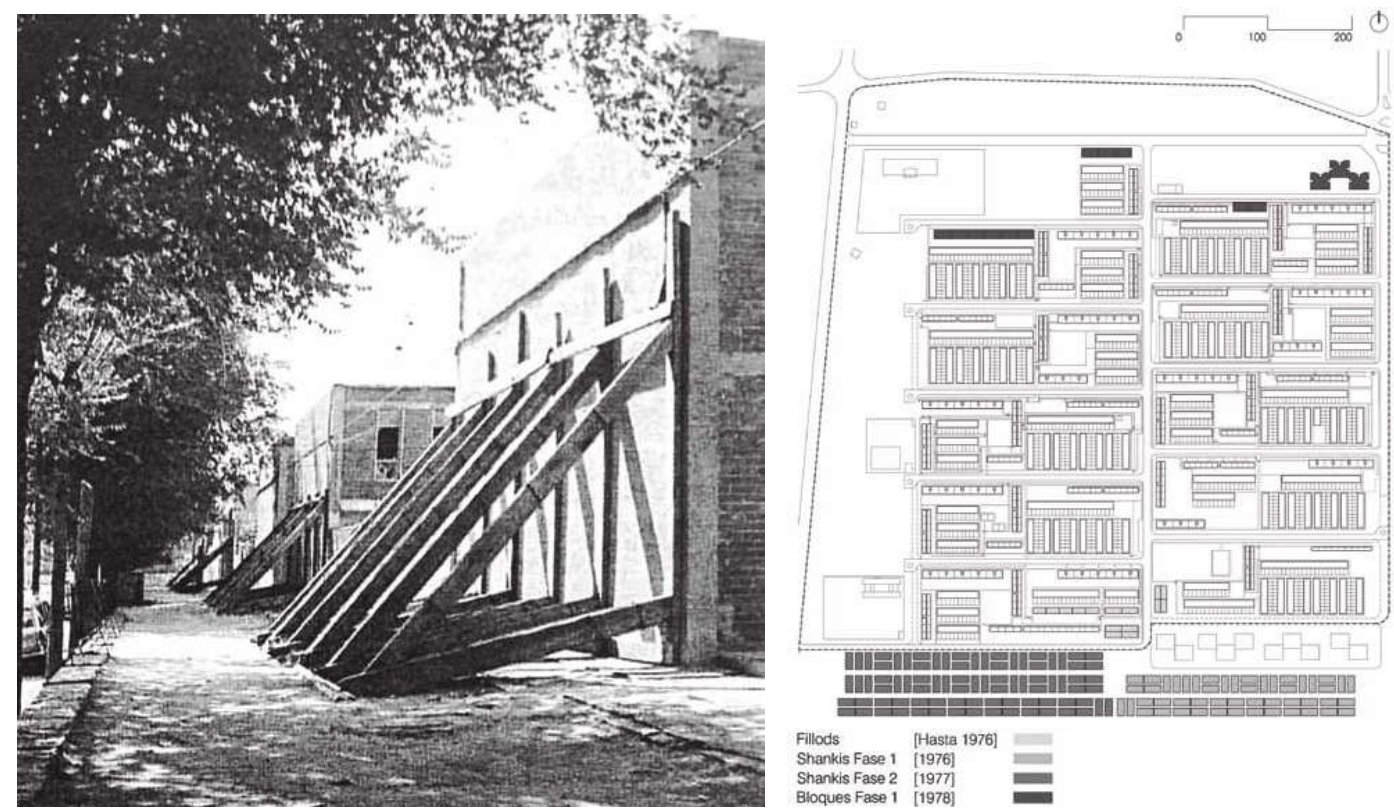

FIG. 5/ Estado de las viviendas unifamiliares, 1961, y situación de las viviendas de realojo durante la remodelación.

Fuente: MANZANO, 1979, p. 637 y elaboración propia

${ }^{16}$ Los criterios de ordenación de los barrios del Plan no son coincidentes con su marco de referencia, el Plan General de 1963, de carácter desarrollista, y se proyectan, soslayando sus determinaciones o tramitando modificaciones, en paralelo al Plan General de 1985, que asimila estos cambios y da coherencia a la estructura general.

${ }^{17}$ Como cita Martin Arnoriaga (1987, pp. 187-188) "[...] mediante una actividad continua de los propios vecinos para es- tudiar y elegir cada opción, decidimos cómo tiene que ser nuestro barrio, construimos y diseñamos nuestra ciudad. También las viviendas con sus materiales y sus características. E incluso actuamos así para la construcción de colegios, guarderías, centro cívico, etc." Esta determinación de la población llega en un momento en el que la participación ciudadana en el urbanismo es objeto de debate alimentado por la COPLACO entre gestores, políticos y técnicos (MoYA, 2011, p. 9). 
de distinto tipo, shankis ${ }^{18}$, y se ubican en una parcela calificada como espacio verde al sur del poblado (FIG. 5). Con el fin de completar todas las viviendas de realojo necesarias para desarrollar la intervención, se construye una primera fase de la remodelación, que es ocupada sucesivamente por la población afectada ${ }^{19}$. Esta fase se proyecta conforme a las alineaciones del Plan Parcial de 1970, aprovechando la edificabilidad disponible generada en este documento, lo que permite acelerar el proceso ${ }^{20}$. El proyecto, que se pone en marcha tras la aprobación del Decreto 323/1976, de 23 de enero, se encarga por adjudicación directa a Juan Capella Callis con dirección de obra a cargo del INV ${ }^{21}$, y comienza a construirse en octubre de ese mismo año. Comprende tres torres de $\mathrm{PB}+11$ y tres bloques de $\mathrm{PB}+6$, con 264 viviendas de Protección Oficial Subvencionadas, aprobadas por Decreto 2114/1968, de 24 julio, con normas de diseño según la Orden de 20 de mayo de $1969^{22}$ (FIGs. 5 y 6 ).

Las fases segunda a quinta sustituyen la edificación residencial, conforme a una Modificación del Plan Parcial redactada en 1978 por los arquitectos José Ignacio Casanova Fernández y Manuel Gutiérrez Plaza y aprobada en $1979^{23}$, que se desarrolla entre 1977 y 1986 con cuatro proyectos realizados por ellos ${ }^{24}$. Este documento mantiene las condiciones básicas del Plan Parcial de 1970 en lo que se refiere a zonificación y usos, e introduce, atendiendo a los intereses de la población, un incremento de edificabilidad residencial. En favor de la viabilidad de la remodelación, deja abierto el desarrollo de las fases para concretarlo a medida que avanza la obra, lo que permite su adaptación al estado crítico de la
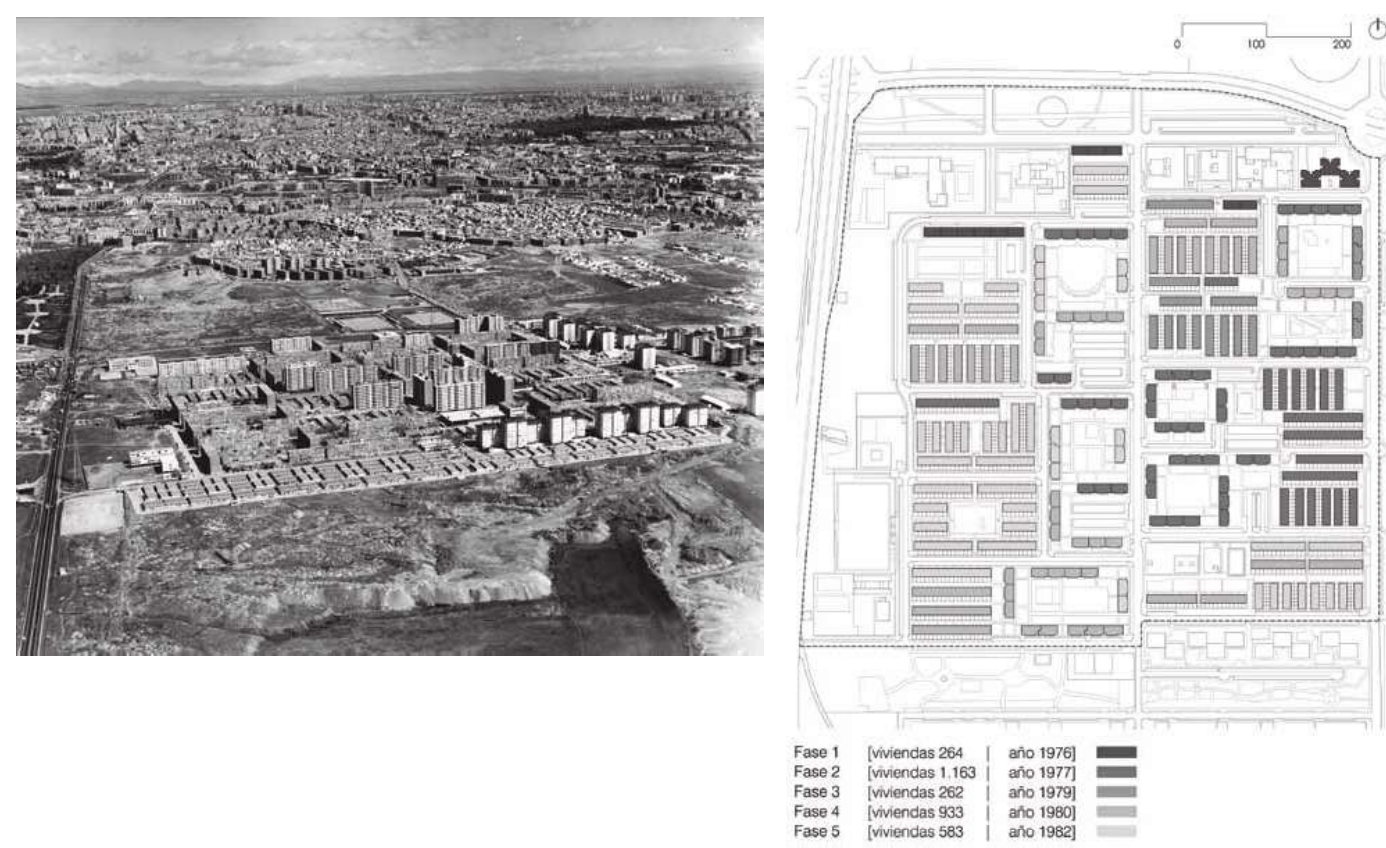

FIG. 6/ Poblado Dirigido de Orcasitas en proceso de remodelación, 1980, y fases del proceso, 1976-1986.

Fuente: E. HERNÁNDEZ y elaboración propia.

\begin{abstract}
${ }^{18}$ Estas viviendas provisionales (273 shankis) se muestran en el Programa de Acción Inmediata (PAI) que la COPLACO como organismo metropolitano con competencias en urbanismo hasta la creación de las autonomías, realiza entre 1978 y 1980 para diagnosticar la situación del Área Metropolitana y elaborar propuestas (FERNÁNDEZ SALGADO, 2011, pp. 28-29). 19 Una vez utilizadas las viviendas para el trasvase de población durante la remodelación, al quedar vacías son reclamadas para los hijos de los vecinos por orden de prioridad: casados, hijos, situación económica ajustada.

${ }^{20} \mathrm{EI}$ PAI (COPLACO, 1979) refleja las alineaciones aprobadas en el Plan General de 1963, la edificación temporal de realojos y la previsión de edificación de la primera fase de remodelación.
\end{abstract}

\footnotetext{
${ }^{21}$ Proyecto de la primera fase de 1976, consultado en el Centro de documentación del COAM y en el Archivo del IVIMA.

${ }^{22}$ Adaptación de las Ordenanzas Técnicas y Constructivas, aprobadas por Órdenes de 12 de julio de 1955 y 22 de febrero de 1968, al texto refundido y revisado de la legislación de Viviendas de Protección Oficial y su Reglamento.

${ }^{23}$ Modificación del Plan Parcial de Ordenación del Poblado de 1978, consultada en el Archivo de la Delegación de Patrimonio del IVIMA.

${ }^{24}$ Primer Proyecto del año 1977 con 1.166 viviendas; segundo de 1979 con 262 viviendas; tercero de 1980 con 933 viviendas y cuarto de 1982 con 583 viviendas. Consultados en el Archivo del IVIMA.
} 
edificación original, y al aprovechamiento del suelo liberado. Principalmente al comienzo de la operación, se busca una concentración edificatoria máxima para completar áreas en las que la población pueda desarrollar la vida con normalidad (FIG. 6). Los realojos de carácter definitivo, se realizan siguiendo la condición vecinal de ubicarse lo más cerca posible de la vivienda de origen, intentando mantener la misma tipología edificatoria y posición relativa.

El nuevo poblado mantiene un funcionamiento en retícula con ejes de distribución, y núcleo residencial flanqueado por equipamientos en áreas de transición hacia el exterior (FIG, 7). Su configuración responde a un uso prioritario del automóvil en los viales principales, que funcionan como ejes distribuidores con posición central y lateral, y en las vías secundarias, cuyo trazado trata de reducir la incidencia del tráfico en las manzanas residenciales y acoger la mayor cantidad de aparcamientos. Respecto a los equipamientos, se construyen aquellos programados en la Operación de Barrios en Remodelación, con lo que se cubren las necesidades de la población, manteniendo su separación funcional respecto al uso residencial ${ }^{25}$ o a cualquier espacio de uso productivo que queda fuera del poblado. Con estas medidas se desaprovecha la oportunidad de reducir la presencia del vehículo en el espacio urbano y dinamizarlo, rompiendo su monofuncionalidad.
La edificación residencial conserva las dos tipologías del poblado original: en altura, con bloques lineales de $\mathrm{PB}+10$ elevados sobre pilotis,y en superficie, con viviendas unifamiliares de $\mathrm{PB}+1$ cuya distribución queda definida en áreas de movimiento, con el fin de aportar flexibilidad durante el proceso. Se construyen un total de 2.944 viviendas sociales, conforme a las disposiciones del Real Decreto 1133/1984, de 22 de febrero, con normas de calidad reguladas por la Orden de 24 de noviembre de 1976. Los módulos correspondientes a este tipo de protección plantean un problema con las 1024 viviendas unifamiliares cuyo coste resulta aproximadamente un $25 \%$ superior que, ante su demandada por parte de la población, aunque se reducen en número respecto a las iniciales, se consideran un compromiso previo adquirido.

Esta medida unida al crecimiento en altura de los bloques, suponen una concentración volumétrica con un incremento de la edificabilidad de un $50 \%$ y una reducción de la ocupación de suelo de un $10 \%$. El aumento de edificabilidad, admisible por los bajos valores de partida, es consecuencia de un importante incremento de la superficie construida de las viviendas que uniformizan sus tipologías. Esta decisión, en principio beneficiosa para los adjudicatarios, muestra sin embargo una falta de adaptación a las nuevas necesidades del conjunto, en el que se detecta una reducción del
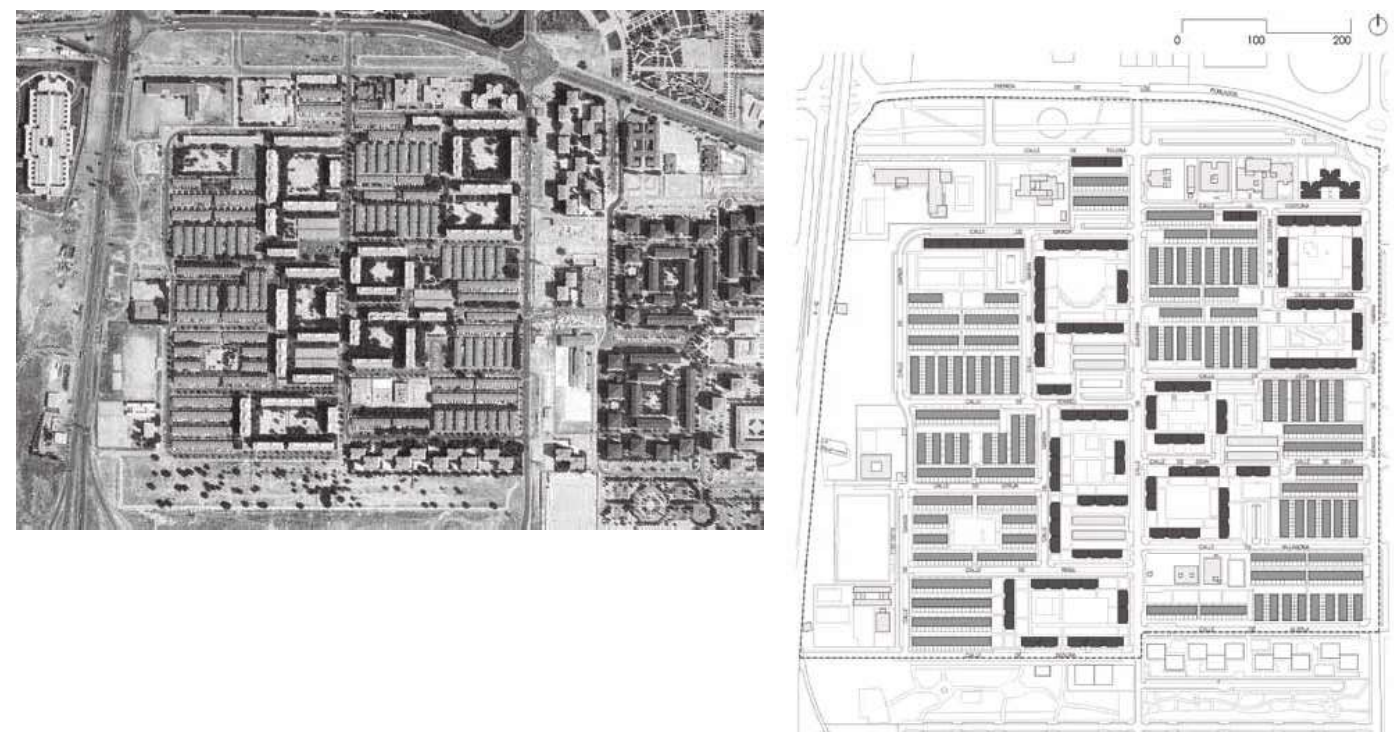

|G. 7/ Poblado Dirigido de Orcasitas tras la remodelación, 1991.

Fuente: Sistema de Información Territorial del Instituto de Estadística de la Comunidad de Madrid y elaboración propia.

\footnotetext{
${ }^{25}$ Con la excepción de los espacios de uso comercial, que ocupan una posición central, en núcleos vinculados al eje del conjunto.
} 
tamaño de las unidades convivenciales, en ocasiones con dificultades económicas para asumir el mantenimiento de los inmuebles (RODRíGUEZ VILLASANTE, 1989, p.134). La menor ocupación de suelo permite llevar a cabo otra premisa demandada por los vecinos, que consiste en liberar la máxima cantidad de espacio de uso público en las manzanas residenciales. Su ordenación se concreta a medida que avanza la remodelación, vinculando el espacio libre a los bloques, para separarlos entre sí y respecto a las viviendas unifamiliares, sin tener en cuenta otros factores que aporten una mayor adecuación de estos espacios a la actividad de sus usuarios (FIG. 8). Tanto la edificación residencial, de construcción modular prefabricada, como los espacios exteriores vinculados a ella, en los que predomina una urbanización con un alto nivel de acabado, se conciben en base a criterios prácticos, y desatienden cuestiones destinadas a añadir diversidad, capacidad de socialización o sostenibilidad ${ }^{26}$.

En definitiva, los objetivos que impulsan el nuevo proyecto se alejan de la experimentación social, plástica y urbana (AmAnN, 2011) que Rafael Leoz y Joaquín Ruiz Hervás aportaban en el poblado original y priman la calidad material de la que se han visto privados durante años.

\section{Conclusiones}

La remodelación del Poblado Dirigido de Orcasitas (1976-1986) supone una conquista del espacio urbano cuyo verdadero motor es la participación. Esta intervención se analiza desde sus particulares circunstancias, en relación a la Operación de Barrios en Remodelación de Madrid, una operación territorial planteada para incorporar a la ciudad las áreas más deprimidas de la periferia. En ella, la población organiza, coordina y ejecuta la renovación urbana a través de la Administración, que introduce un modo de actuación adaptado a su demanda. Esta forma de proceder tiene lugar en un momento muy determinado, en la transición española hacia la democracia, ante el desconcierto del Estado por la conflictividad social y repercusión de la situación.

El aspecto fundamental que pone en marcha la remodelación del Poblado Dirigido de Orcasitas es la iniciativa vecinal que participa del proceso reivindicativo general, ante las condiciones de la

${ }^{26}$ Reflexión que, independientemente de la calidad arquitectónica de los conjuntos, ha sido anteriormente realizada en relación a otros barrios de la Operación como son Palomeras (VILlanUeVA, 1989) y Zofío (ColAVIDAs, 1981) y que continúa edificación del poblado y las amenazas de expulsión de un territorio que percibe como propio. La continua defensa de los intereses de la población debe su éxito a la Asociación de Vecinos, que ocupa una posición destacada y mantiene una presencia constante, realizando una labor de mediación y organización. El papel de la población en los distintos ámbitos que condicionan el proceso permite considerar esta experiencia como un ejemplo de lucha vecinal, precursora del actual urbanismo participativo.

La intervención da comienzo de forma aislada, sin el marco legislativo y jurídico necesario y afianzando el modelo del Programa de Barrios en Remodelación, que se implanta mediante una Orden Comunicada en 1979 y se consolida definitivamente en 1984. Esta normativa da cuerpo legal a compromisos adquiridos o situaciones de hecho $\mathrm{y}$, ante la excepcionalidad del proceso, va por detrás de las primeras experiencias, como la remodelación del Poblado Dirigido, cuyas reivindicaciones se ven reflejadas en ella.

La Administración responde ante la iniciativa de la población residente, asumiendo la gestión y promoción de las obras de construcción y urbanización del nuevo poblado, en un tipo de colaboración singular. Los vecinos exceden el ámbito de la participación y asumen funciones de planificación, administración y control con una organización propia, que a partir de 1981 se regula para todos los barrios de la Operación.

La financiación del Programa de Remodelación depende de los presupuestos públicos, cuya renovación fraccionada hace imposible una planificación global. Esta circunstancia genera en el Poblado Dirigido una cierta desconfianza en la finalización del proceso, debido a que carece de referentes de actuación previa. Sin embargo, al afrontar la remodelación en un momento temprano y ocupar una posición destacada en las negociaciones con las entidades públicas implicadas, recibe unos beneficios importantes y una inversión superior a la media de los barrios en los que se actúa.

La intervención en el poblado se inicia sin un instrumento de planeamiento específico para acelerar su ejecución y posteriormente se rige por mecanismos capaces de aportar la flexibilidad suficiente para darle viabilidad, como es habitual en el Programa. La urgencia y complejidad del

siendo aplicable en periferias residenciales producidas en las últimas décadas en el área metropolitana de Madrid (LOPEZ DE Luclo, 2004, p. 80). 

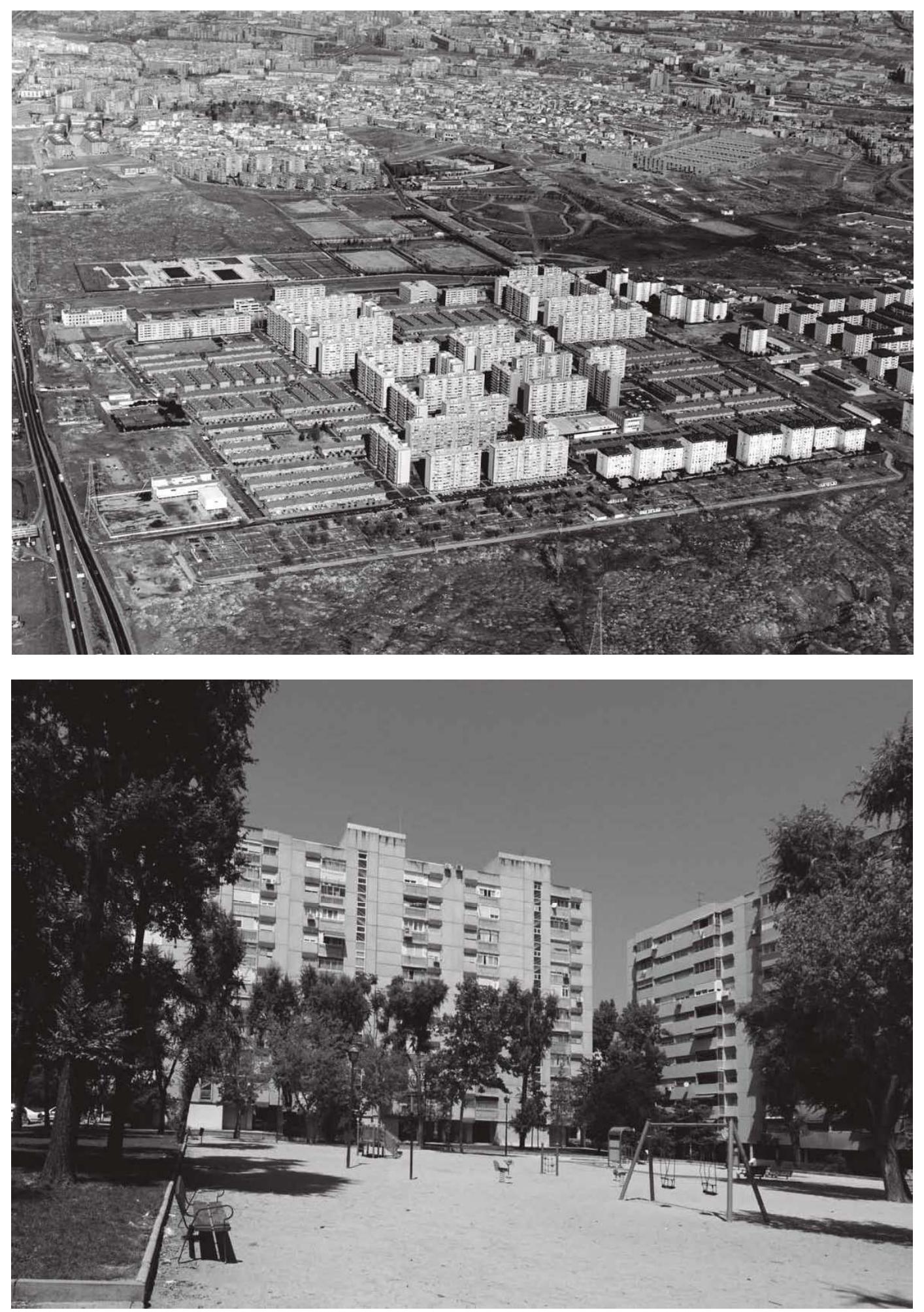

FIG. 8/ Poblado Dirigido de Orcasitas tras la remodelación, 1986 y 2018.

Fuente: E. HERNÁNDEZ y elaboración propia. 
proceso y la capacidad de decisión de los vecinos, condicionan la estructura urbana, la edificación y el espacio público, con un proyecto que prima la calidad material del cambio físico, pero no favorece un cambio social capaz de mejorar el nivel de vida de la población.

La remodelación del Poblado Dirigido de Orcasitas constituye por tanto un modelo de intervención en el que la participación vecinal influye de una manera determinante en el marco legislativo y jurídico, la gestión, la financiación y la configuración del nuevo barrio. Su desarrollo bajo una confluencia de circunstancias enmarcadas en un momento histórico y un entorno físico determinados, dan lugar a un resultado que, aunque no es replicable ni formalmente ejemplar, tiene un importante valor como impulsor del cambio urbano.

\section{Bibliografía}

Amann Alcocer, A. (2011): «Poblado Dirigido de Orcasitas», en GIVCO: Poblado Dirigido de Orcasitas (Fases I y II): Rafael Leoz de la Fuente, Joaquín Ruiz Hervás, Madrid 1957-66. Cuadernos de Vivienda, 7.

BLos, D. (1999): Los polígonos de vivienda social: Perspectivas hacia su recuperación en España, Francia y Brasil (Tesis doctoral): Universitat Politècnica de Catalunya.

BRANDIS, D. (1983): El paisaje residencial en Madrid. MOPU/ DGATU, Madrid

Castells, M. (1981): Crisis urbana y cambio social. Siglo XXI de España, Madrid.

CAstells, M. (1991): «El auge de la ciudad dual: teoría social y tendencias sociales», en: ALFOZ, 80: 89-103

CAstro, P. \& MolinA, J. (1996): «Un ejemplo de participación y renovación urbana: la remodelación de barrios en Madrid (España)», en: Ciudades para un Futuro más Sostenible. Consulta: 12.01.2018. Disponible en:

http://habitat.aq.upm.es/dubai/96/bp258.htm

ColAVIDAS EsPINOSA, F. (1981): «Aspectos relacionados con el proceso de participación vecinal en el proceso de remodelación de la Colonia de Zofio», en: BODEN, 23-24: 97-102.

COPLACO (1979): Programa de Acción Inmediata Usera Villaverde: Estudio Urbanístico de los barrios 123, 124, 125 del municipio de Madrid (PAI Usera Villaverde). Madrid.

DAVIDOFF, P. (1965): «Advocacy and Pluralism in Planning», en: Journal of the American Institute of Planners, 31, 4: 331-338.

Denche Morón, C. \& Rodríguez Villasante, T. (1987) "Modos de vida y Urbanismo», en: ALFOZ, 39: 28-32.

Denche Morón, C. \& Alguacil Gómez, J. (1991): «La experiencia de los barrios en remodelación y las políticas de realojamiento», en: Documentación social, 85:139-152.

Diez de PABLo, A. (2015): La vivienda social como patrimonio urbano. Análisis de la patrimonialización de tres Barrios de Promoción Oficial madrileños
(Tesis doctoral): Universidad Politécnica de Madrid. Fernández Galiano, L. \& Fernández De IsAsi, J. \&. Lopera Arazola, A. (1989): La quimera moderna. Hermann Blume, Madrid.

Fernández Salgado, C. (2011): «Democracia y participación: el Plan General de Madrid de 1985», en: Cuadernos de Investigación Urbanística, 79: 6-68.

GómEZ-MoRÁn \& CIMA, M. (1972): Sociedad sin vivienda. Fundación Foessa, Madrid.

Hernández Aja, A. \& Velázquez, I. (1987): «Pisos, canes y barrio», en: ALFOZ, 39: 37-39.

HeRnÁNDEZ, E. (1981): «Entrevista a D. Eduardo Hernández. Arquitecto. Asesor de la Coordinadora Vecinal», en: BODEN, 23-24: 82-86.

- (1987): «Remodelación, cuerda para rato», en: ALFOZ, 39: 40-43.

LASSO LICERAS, L. (1981): «El proceso de remodelación y crecimiento en la periferia obrera de Madrid», en: $B O D E N$, 23-24: 7-71.

Leoz De La Fuente, R. \& Ruiz Hervás, J. (1961a): «El poblado de Orcasitas», en: TA. Temas de Arquitectura y Urbanismo, 22: 856-867.

- (1961b): «El poblado de Orcasitas (Cont.)», en: TA. Temas de Arquitectura y Urbanismo, 27: 922-926.

Lefebvre, H. (1978): El derecho a la ciudad. Península, Barcelona.

LeÓN, C. \& AlguACIL, J. (1987): «Los protagonistas de la remodelación», en: $A L F O Z, 39: 33-36$.

LÓPEZ DE LucIo, R. (1981): «Entrevista a D. Ramón López de Lucio. Arquitecto-urbanista, componente del equipo responsable de la remodelación del Pozo del Tío Raimundo», en: BODEN, 23-24: 72-81.

- (2004): «Morfología y características de las nuevas periferias: nueve paisajes residenciales en la región urbana de Madrid», en: URBAN, 9: 56-80.

- (2013): Vivienda colectiva, espacio público y ciudad: evolución y crisis en el diseño de tejidos residenciales, 1860-2010. Nobuko: Buenos Aires.

MANGADA, E. (1987): «No se ha ralentizado el programa de vivienda, al contrario, éste se ha incrementado», en: $A L F O Z, 39: 49-54$.

MANZANO MARTOS, J. (1979): «Orcasitas», en: VV.AA Madrid, vol. II, Espasa Calpe, Madrid: 621-640.

MartinArnoriaga, T. (1986): Del barro al barrio. La Meseta de Orcasitas. Asociación de Vecinos de Orcasitas, Madrid.

Moya GonzÁlez, L. (1983): Barrios de Promoción Oficial. Madrid 1939-1976. COAM, Madrid.

- (1987): Análisis del Proceso de Remodelación y Realojamiento de Barrios en Madrid. ETSAM/ IVIMA, Madrid.

— \& al. (S/F): Barrios de Promoción Oficial de la Operación de Remodelación. Madrid 1979-1986. Documento de trabajo IVIMA, Consejería de Ordenación del Territorio, Medio Ambiente y Vivienda Comunidad de Madrid, Madrid.

Moya GonzÁlez, L. \& Fernández Salgado, C. (2011): «La participación ciudadana en la Operación de Remodelación y Realojo de Barrios de Madrid», en: Actas /cono 14, II Congreso Internacional Sociedad Digital, 8.

ORGANIZACIÓN PARA LA COOPERACIÓN Y EL DESARROLLO ECONÓMICO (1988): Grupo de Proyectos sobre mercados de Suelo Inmobiliario: Estudio Marco sobre Madrid, España. Documento de trabajo, París.

Rodríguez VilLasante, T. \& al. (1989): Retrato de chabolista con piso. Análisis de redes sociales en la remodelación de barrios de Madrid. ALFOZ-CIDUR/ 
IVIMA-SGV, Madrid.

Serrano Alcudia, F. (1999): Patología de la Edificación: El lenguaje de las grietas. Fundación Escuela de la Edificación, Madrid.

VILLANUeVA, A. (1989): «Encuesta», en: ALFOZ, 66, 47-48.
VINUESA ANGULo, J. (1987): «La gestión: un proceso singular», en: ALFOZ, 39: 3-12.

- \& SÁnchez-Fayos, T. \& Oliete, A. (1986): «La Operación de Remodelación de Barrios de Madrid», en: Ciudad y Territorio, 68: 71-88. 